\title{
The Amino Thiourea-Catalyzed Asymmetric Nucleophilic Reactions
}

\author{
Yoshiji Takemoto* and Hideto Miyabe
}

\begin{abstract}
Bifunctional amino thiourea-catalyzed asymmetric additions of several nucleophiles into electrondeficient unsaturated compounds such as nitroolefins, $\alpha, \beta$-unsaturated imides, imines, and azodicarboxylates are described. We discovered that bifunctional thioureas bearing a tertiary amino group significantly accelerated several nucleophilic addition reactions of active methylene compounds to electron-deficient double bonds. In these reactions, a strong hydrogen-bonding ability of the thiourea moiety as well as an appropriate Brønsted basicity of the tertiary amine is crucial for high enantioselectivity. This dual activation of both nucleophiles and electrophiles by the bifunctional thiourea expanded the applicability of the thiourea-catalyzed enantioselective reaction. In addition, these organocatalyzed asymmetric reactions were successfully applied to the concise asymmetric synthesis of natural products and medicinal candidates such as epibatidine, baclofen, and CP-99,994.
\end{abstract}

Keywords: Asymmetry · Catalysis · Imine · Malonate · Nitroolefin · Thiourea

\section{Introduction}

Urea and thiourea derivatives have been intensively investigated in the area of molecular recognition due to their strong hydrogen-bonding ability. They can be used to recognize carboxylic acids, sulfonic acids, nitrates, and others through multi-hydrogen bonding interaction. On the other hand, since Kelly et al. and Etter et al. reported that urea and thiourea not only recognized organic compounds but also activated them as a general acid catalyst, ${ }^{[1,2]}$ novel urea and thiourea derivatives have been developed for a variety of diastereo- and enantioselective reactions and their versatility as a general acid has been successfully demonstrated by several groups..$^{[3-7]}$ However, the application of these catalysts to asymmetric reactions seems to be somewhat limited, because ureas are weaker acids than metallic Lewis acids. To overcome this problem, we recently designed and prepared a bifunctional thiourea catalyst bearing a tertiary amino group (Fig. 1). These thioureas were designed based on the mechanism of serine protease, which is known as a hydrolytic enzyme. The dual-activation protocol of electrophile and nucleophile by bifunctional thioureas was generally applicable to a variety of catalytic asymmetric reactions. ${ }^{[8]}$ In this account, we offer a comprehensive overview of our recent studies on bifunctional thiourea-mediated asymmetric nucleophilic reactions.

\section{Design of Chiral Bifunctional Amino Thiourea Catalysts}

Since Curran and co-workers' pioneering work, ${ }^{[4]}$ various types of nucleophilic addition reaction have been shown to be effectively promoted by a catalytic amount of well-designed ureas and thioureas by several research groups. ${ }^{[3]}$ However, there is only limited information on how to design a chiral urea/thiourea catalyst for asymmet- ric reactions. We prepared a wide range of thioureas bearing a tertiary amino group in expectation of their dual activation ${ }^{[9]}$ of both electrophiles and nucleophiles to promote several nucleophilic addition reactions. It is assumed that weak tertiary amine bases can coexist with the thiourea moiety in a molecule without deactivating each other.

Based on the results of Schreiner and co-workers' achiral diarylthiourea catalyst $1,^{[5]}$ a variety of bifunctional amino thioureas such as $\mathbf{2 a}-\mathbf{d}$ were designed and synthesized by the replacement of the 3,5-bis(trifluoromethyl)phenyl group of diaryl thiourea 1 by cyclic and acyclic 2(N,N-dimethylamino)ethane derivatives as a chiral scaffold (Fig. 2). To compare the reactivity and selectivity between thiourea and amide, bifunctional amide 2e was also prepared. Furthermore, we also synthesized thiourea catalysts $\mathbf{4 a - c}$ anchored to several polymer supports such as PEG, carboxypolystyrene HL, and TentaGel carboxy resins. Such immobilization facilitates the re-

\footnotetext{
${ }^{*}$ Correspondence: Prof. Dr. Y. Takemoto

Graduate School of Pharmaceutical Sciences

Kyoto University

Yoshida, Sakyo-ku

Kyoto 606-8501

Japan

Tel.: +81757534528

Fax.: +81757534569

E-Mail: takemoto@pharm.kyoto-u.ac.jp
}

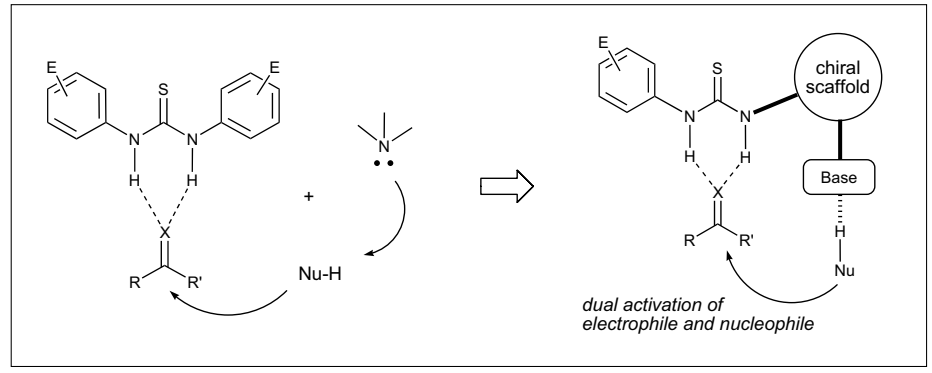

Fig. 1. Design of bifunctional thioureas bearing an amino group 
covery and reuse of precious catalysts from the reaction mixture by simple filtration. For that purpose, we prepared the amino thiourea 3 introducing a carboxylic acid in the place of the trifluoromethyl group to attach the thiourea to several polymer supports. In a case of the cross-linked polystyrene resin-bound thioureas $\mathbf{4 a}, \mathbf{b}$, a carbonchain spacer derived from pentane-1,5-diol was introduced to enhance their catalytic activity $(0.79 \mathrm{mmol} / \mathrm{g}$ and $0.19 \mathrm{mmol} / \mathrm{g}$ loading levels, respectively). On the other hand, a soluble immobilizing catalyst $\mathbf{4 c}$ was prepared by directly connecting two amino thiourea moieties to poly(ethylene glycol)(PEG 8000). The purity of the catalyst was determined to be $c a$. $80 \%$ by ${ }^{1} \mathrm{H}$ NMR analysis. ${ }^{[10]}$

\section{Asymmetric Michael Reaction to a Electron-deficient $\mathbf{C}=\mathbf{C}$ Double Bond}

Ureas and thioureas are good hydrogenbonding donors not only for anions but also neutral compounds. Among such neutral compounds, nitrobenzene derivatives were proved to form eight-membered hydrogenbonding with diarylthiourea by cocrystallization experiments. ${ }^{[2 \mathrm{c}]}$ We explored the Michael reactions of nitroolefins and $\alpha, \beta$-unsaturated imides with several active methylene compounds such as malonates, $\beta$-ketoesters, and malononitrile, which would be deprotonated by the tertiary amino group.

\subsection{Enantioselective Michael Addition of 1,3-Dicarbonyl Compounds to Nitroolefins}

The Michael reaction ${ }^{[11]}$ of $\beta$-nitrostyrene 5 was carried out in toluene with 2 equiv. of diethyl malonate and $10 \mathrm{~mol} \%$ of

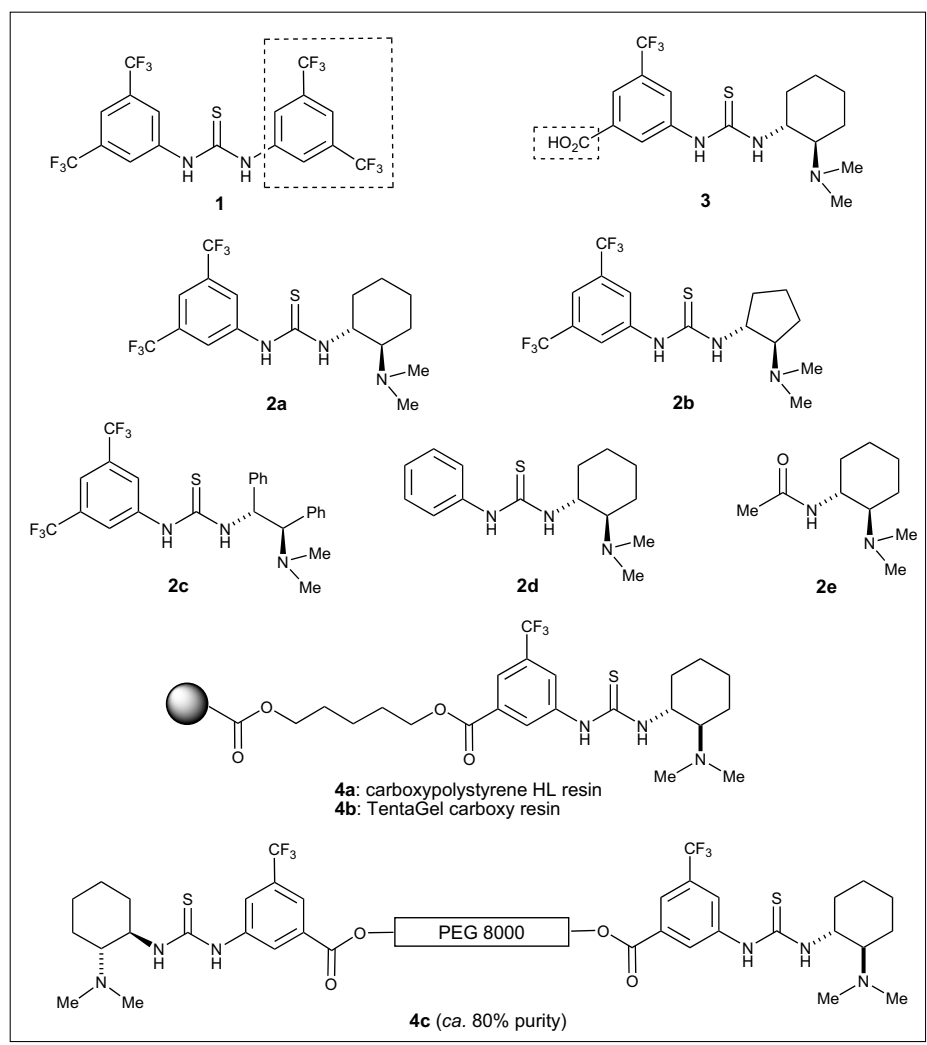

Fig. 2. Bifunctional thioureas $\mathbf{2 a}-\mathbf{d}$, amide $\mathbf{2 e}$, and polymer-supported thioureas $4 a-c$

catalysts $2 \mathbf{a}-\mathbf{e}$ (Table 1). ${ }^{10 a, b}$ As expected, thiourea 2a gave the best result in terms of chemical yield and enantioselectivity. These results indicated that both rigidity of the chiral diamine scaffold and cooperative function of two N-H bonds and the tertiary amino group in the catalyst were crucial for the enantioselective Michael reaction (entries 1-5). To survey the potency of immobilized thiourea catalysts for their recovery and reuse, the same reaction was performed in $\mathrm{CH}_{2} \mathrm{Cl}_{2}$ with polymer-supported thioureas $\mathbf{4 a}-\mathbf{c} .^{[10 \mathrm{c}]}$ Although the resin-bound catalysts $\mathbf{4 a}, \mathbf{b}$ showed lower catalytic activities as compared to the soluble catalyst 2a, the Michael reaction with the PEG-bound 4c afforded the desired product 7 in $71 \%$ yield with $86 \%$ ee. Furthermore, catalyst 4c was easily recovered by the addition of diethyl ether to the reaction mixture, and reused without further purification to give the same adduct in comparable yield and selectivity (entries 6-9).

Further studies on the Michael addition demonstrated that 1,3 -diketone and $\beta$-ketoesters as well as $\alpha$-substituted malonates
Table 1. Thiourea-catalyzed Michael addition to $\beta$-nitrostyrene 5

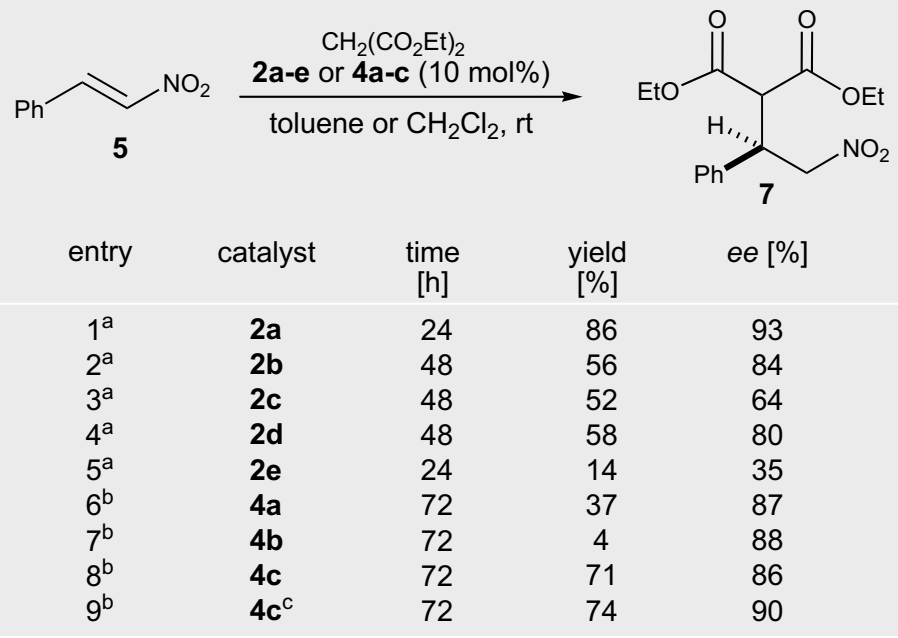

${ }^{a}$ Reaction was carried out in toluene. ${ }^{b}$ Reaction was carried out in $\mathrm{CH}_{2} \mathrm{Cl}_{2}$. ${ }^{\mathrm{C}}$ Recovered catalyst $4 \mathrm{c}$ was used.

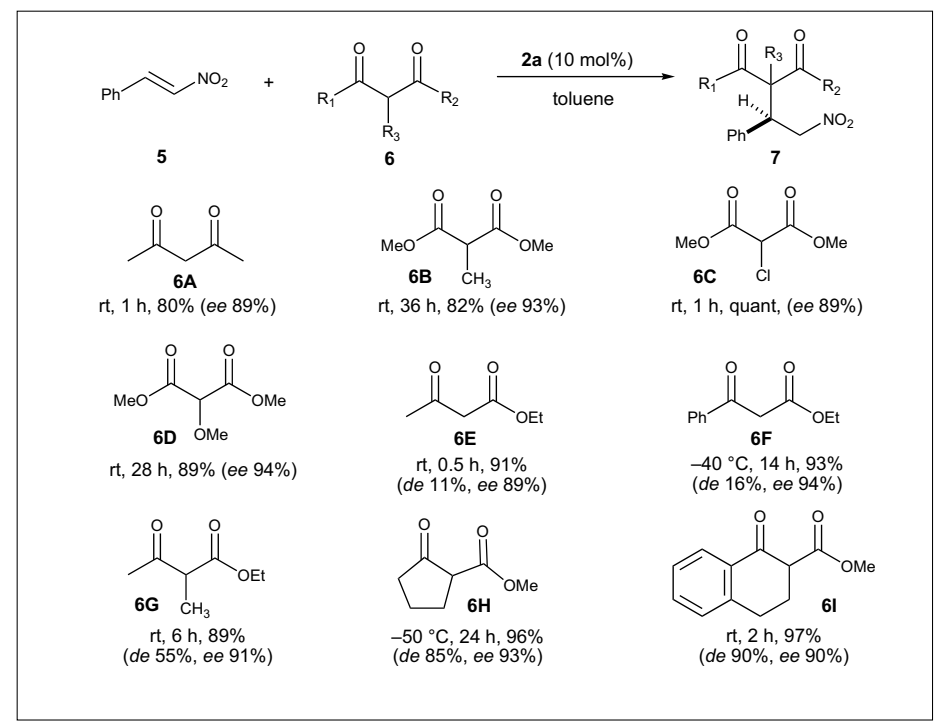

Scheme 1. Thiourea-catalyzed Michael addition of 1,3-dicarbonyl compounds $\mathbf{6}$ to $\beta$-nitrostyrene 5 


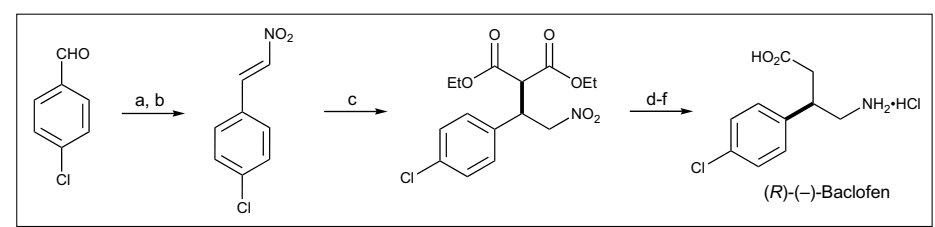

Scheme 2. Reagents and Conditions: (a) $\mathrm{MeNO}_{2}, \mathrm{NaOMe}, \mathrm{MeOH}, \mathrm{rt}, 15 \mathrm{~h}$, 90\%; (b) MsCl, Et ${ }_{3} \mathrm{~N}, \mathrm{THF}, \mathrm{rt}, 1 \mathrm{~h}, 72 \%$; (c) Diethyl malonate, 2a, toluene, rt, $24 \mathrm{~h}, 80 \%$ (>99\% ee after single recrystallization from hexane/AcOEt); (d) $\mathrm{NiCl}_{2} \cdot 6 \mathrm{H}_{2} \mathrm{O}, \mathrm{NaBH}_{4}, \mathrm{MeOH}, \mathrm{rt}, 7.5 \mathrm{~h}, 94 \%$; (e) $\mathrm{NaOH}$, EtOH, rt, 45 h; then toluene, reflux, $6.5 \mathrm{~h}, 84 \%$; (f) $6 \mathrm{~N} \mathrm{HCl}$, reflux, $24 \mathrm{~h}, 94 \%$.

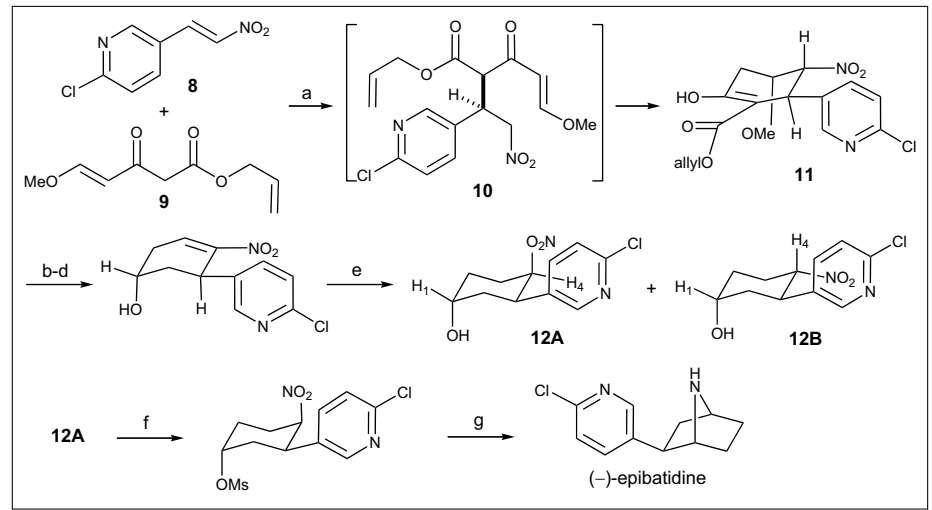

Scheme 3. Reagents and Conditions: (a) 2a, toluene, $0{ }^{\circ} \mathrm{C} ; \mathrm{KOH}, \mathrm{EtOH}, 0$ ${ }^{\circ} \mathrm{C}, 77 \%$ (75\% ee); (b) Pd(OAc) ${ }_{2}, \mathrm{PPh}_{3}, \mathrm{HCO}_{2} \mathrm{H}, \mathrm{Et}_{3} \mathrm{~N}, \mathrm{THF}, \mathrm{rt}, 99 \%$; (c) LSelectride, THF, $-78{ }^{\circ} \mathrm{C}, 71 \%$; (d) NaOMe, tert-BuOH, $71 \%$; (e) $\mathrm{NaBH}_{3} \mathrm{CN}$, $\mathrm{AcOH}, \mathrm{MeOH},-20^{\circ} \mathrm{C}, 87 \%(\mathbf{1 2 A} / \mathbf{1 2 B}=9 / 1)$; (f) $\mathrm{MsCl}, \mathrm{Et}_{3} \mathrm{~N}, \mathrm{DMAP}, \mathrm{CH}_{2} \mathrm{Cl}_{2}$, $0{ }^{\circ} \mathrm{C}, 91 \%$; (g) Zn, AcOH, THF, rt; $\mathrm{CHCl}_{3}, 60{ }^{\circ} \mathrm{C}, 85 \%$.

could be used as a nucleophile to give the corresponding addition adducts 7 in good yields with 89-94\% ee (Scheme 1, 6A-F). It should be noted that the reaction with prochiral nucleophiles such as $\alpha$-substituted $\beta$-ketoesters also occurred in good diastereo- and enantioselective manner, resulting in the construction of contiguous stereogenic centers containing a chiral quaternary carbon $(\mathbf{6 G}-\mathbf{I})$.

Baclofen is a lipophilic analogue of GABA ( $\gamma$-aminobutylic acid), and it is widely used as an antispastic agent in racemic form. We applied the Michael reaction for the synthesis of $(R)-(-)$-baclofen as its hydrochloric salt $(38 \%$ overall yield in six steps from 4-chlorobenzaldehyde) (Scheme 2).

The enantioselective construction of multiple stereogenic centers in a single operation has been the subject of recent research. For this purpose, we planned to develop a tandem Michael addition of $\gamma, \delta$ unsaturated $\beta$-ketoesters to nitroalkenes for the asymmetric synthesis of (-)-epibati-
Table 2. Michael addition of malononitrile to $\alpha, \beta$-unsaturated imides 13<smiles>[R]C(=O)/C=C/c1ccccc1</smiles>

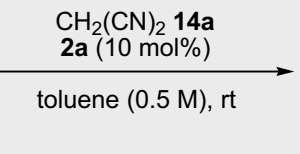<smiles></smiles>

entry

substrate [R]

time [h]

yield (\%)

ee [\%]

1
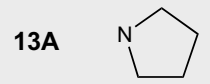

$15 \mathrm{~A}$

48

0

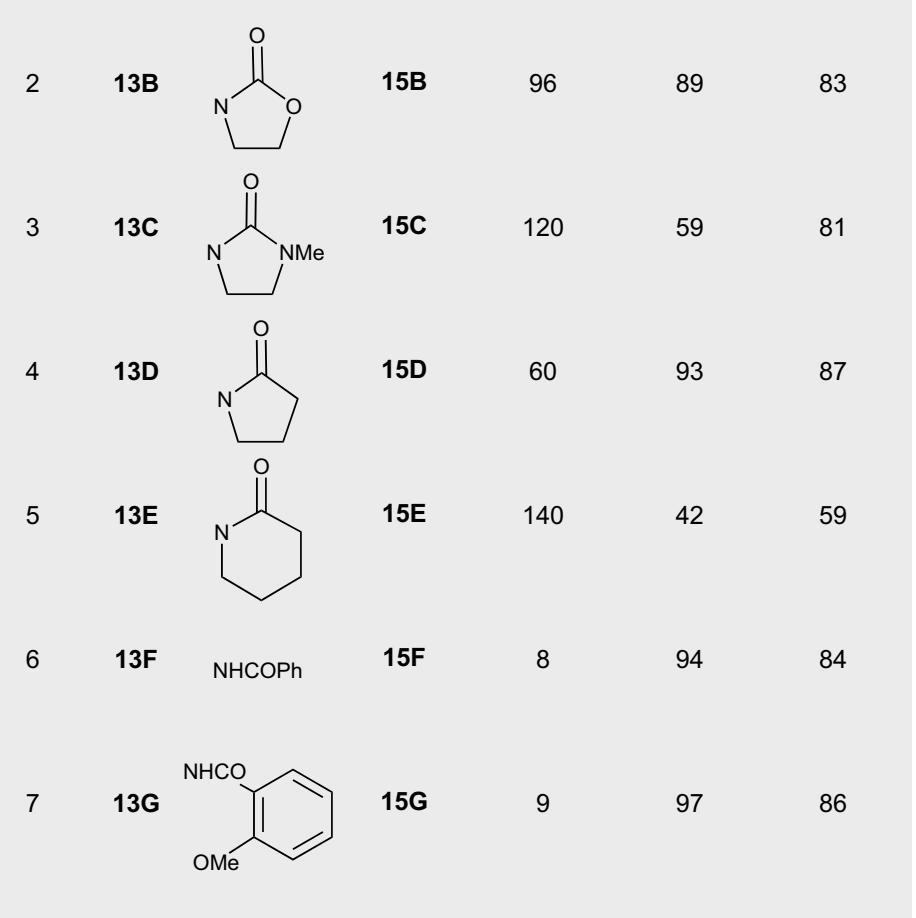

$15 E$

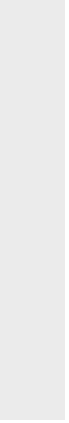

dine, a potent nicotinic acetylcholine receptor agonist (Scheme 3). ${ }^{[12]}$ The subsequent treatment of $\gamma, \delta$-unsaturated $\beta$-ketoester $\mathbf{8}$ and nitroalkene 9 with thiourea $\mathbf{2 a}$ and $\mathrm{KOH}$ gave rise to 3,4-anti-4,5-syn cycloadduct $\mathbf{1 1}$ via Michael adduct 10 with excellent diastereoselectivity, but moderate enantioselectivity. It is worthy to note that this was the first report of successful asymmetric synthesis of three contiguous stereogenic centers by the tandem Michael reaction with nitroalkenes. Consequently, we have succeeded in the total synthesis of (-)-epibatidine in six steps from the Michael adduct $\mathbf{1 1 .}$

\subsection{Enantioselective Michael Reaction to $\alpha, \beta-$ Unsaturated Imides}

Although organocatalysts possessing chiral secondary amines or thioureas have

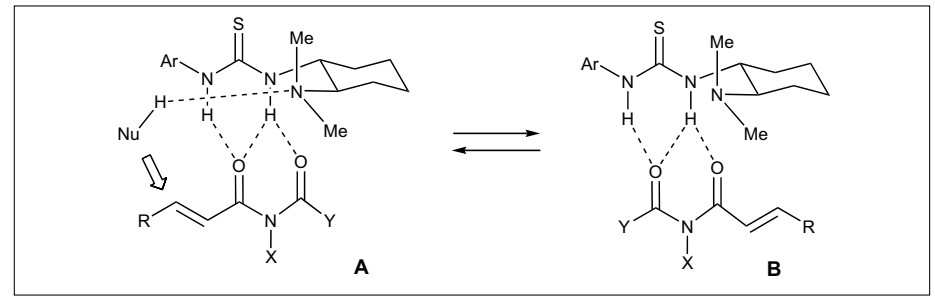

Fig. 3. Hydrogen-bonding interaction between an imide and $\mathbf{2 a}$

proven to be efficient catalysts for the Michael reaction with enones and nitroalkenes, there have been no reports on their application to $\alpha, \beta$-unsaturated acid derivatives. Therefore, the development of general and highly enantioselective versions with $\alpha, \beta$ unsaturated acid derivatives still remains a challenging goal. ${ }^{[13]}$ We investigated the thiourea-catalyzed asymmetric Michael reaction of 1,3-dicarbonyl compounds to $\alpha, \beta$-unsaturated carboxylic acid derivatives based on our previous results with nitroolefins. We expected that an imide moiety could be activated by bifunctional thiourea 2a through double hydrogen-bonding interaction in a similar manner as the nitro group (Fig. 3). Although there would be various types of the hydrogen-bonding interaction between an imide and thiourea $\mathbf{2 a}$ (for example $\mathbf{A}$ and $\mathbf{B}$ ), the reaction should take place via the transition state such as $\mathbf{A}$, where a nucleophile, activated by the amino group of $2 \mathbf{a}$, can attack the $\beta$-position of the imide.

Indeed, among the $\alpha, \beta$-unsaturated acid derivatives 13A-G, N-acyl-2-methoxybenzimide 13G exhibited high reactivity in the Michael addition of malononitrile 14a, that is, the reaction was complete after only $9 \mathrm{~h}$, 
Table 3. Michael addition of several nucleophiles $14 a-c$ to imides 16

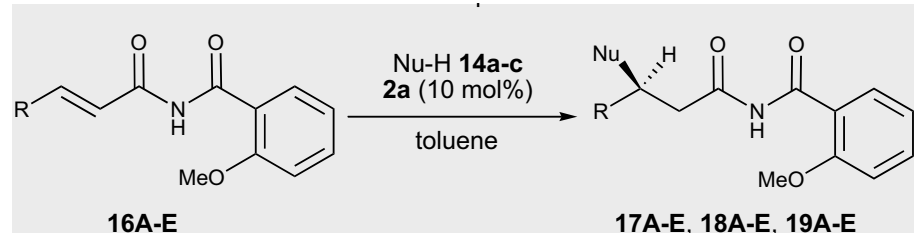

14a: $\mathrm{Nu}=\mathrm{CH}(\mathrm{CN})_{2}$, 14b: $\mathrm{Nu}=\mathrm{CH}(\mathrm{CN})\left(\mathrm{CO}_{2} \mathrm{Me}\right)$, 14c: $\mathrm{Nu}=\mathrm{CH}_{2} \mathrm{NO}_{2}$ A: $\mathrm{R}=\mathrm{Ph}, \mathrm{B}: \mathrm{R}=p-\mathrm{FC}_{6} \mathrm{H}_{5}, \mathbf{C}: \mathrm{R}=p-\mathrm{MeOC}_{6} \mathrm{H}_{5}, \mathrm{D}: \mathrm{R}=\mathrm{Me}, \mathrm{E}: \mathrm{R}=\mathrm{TBSO}\left(\mathrm{CH}_{2}\right)_{5}$

\begin{tabular}{|c|c|c|c|c|c|c|c|}
\hline entry & 16 & 14 & $\begin{array}{c}\text { temp } \\
{\left[{ }^{\circ} \mathrm{C}\right]}\end{array}$ & $\begin{array}{c}\text { time } \\
{[\mathrm{h}]}\end{array}$ & product & $\begin{array}{c}\text { yield } \\
{[\%]}\end{array}$ & $\begin{array}{c}e e \\
{[\%]}\end{array}$ \\
\hline $1^{\mathrm{a}}$ & $16 \mathrm{~A}$ & $14 a$ & $\mathrm{rt}$ & 14 & $17 \mathrm{~A}$ & 95 & 91 \\
\hline $2^{\mathrm{a}}$ & $16 \mathrm{~B}$ & $14 a$ & rt & 7 & 17B & 99 & 92 \\
\hline $3^{a}$ & $16 C$ & $14 a$ & rt & 24 & $17 \mathrm{C}$ & 92 & 90 \\
\hline $4^{a}$ & 16D & $14 a$ & $\mathrm{rt}$ & 3 & 17D & 96 & 90 \\
\hline $5^{a}$ & $16 \mathrm{E}$ & $14 a$ & $\mathrm{rt}$ & 5 & $17 \mathrm{E}$ & 95 & 93 \\
\hline $6^{b}$ & $16 \mathrm{~A}$ & $14 b$ & 80 & 52 & $18 \mathrm{~A}$ & 94 & 82 \\
\hline $7^{b}$ & $16 \mathrm{~B}$ & $14 b$ & 80 & 48 & 18B & 91 & 85 \\
\hline $8^{b}$ & 16D & $14 b$ & $\mathrm{rt}$ & 87 & 18D & 90 & 92 \\
\hline $9^{b}$ & $16 \mathrm{E}$ & $14 b$ & $\mathrm{rt}$ & 137 & $18 \mathrm{E}$ & 96 & 92 \\
\hline $10^{b}$ & $16 \mathrm{~A}$ & $14 c$ & 60 & 168 & $19 A$ & 56 & 87 \\
\hline $11^{b}$ & $16 \mathrm{~B}$ & $14 c$ & 60 & 168 & $19 B$ & 60 & 86 \\
\hline $12^{b}$ & 16D & $14 c$ & $\mathrm{rt}$ & 135 & 19D & 91 & 83 \\
\hline $13^{b}$ & $16 \mathrm{E}$ & $14 c$ & $\mathrm{rt}$ & 256 & $19 \mathrm{E}$ & 82 & 80 \\
\hline
\end{tabular}

a The reaction was carried out in a $0.1 \mathrm{M}$ solution. ${ }^{\mathrm{b}}$ The reaction was carried out in a $0.5 \mathrm{M}$ solution

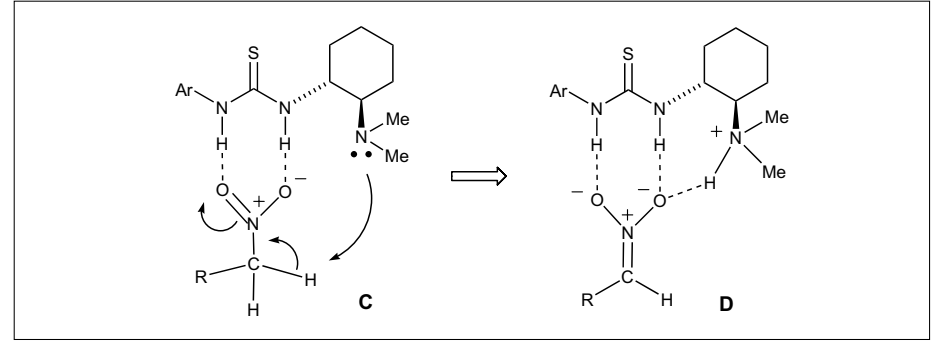

Fig. 4. Generation of a nitronate anion from nitroalkane with $\mathbf{2 a}$

Table 4. Thiourea-catalyzed aza-Henry reaction<smiles>[Pb]N=Cc1ccccc1</smiles>

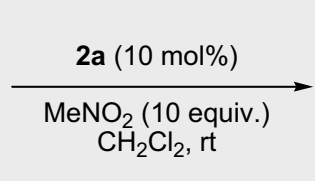

$\mathrm{Cl}_{2}, \mathrm{rt}$<smiles>O=[N+]([O-])CC(N[P+](=O)[O-])c1ccccc1</smiles>

21a-f

$\begin{array}{ccccc}\text { entry } & \text { PG } & \text { time }[\mathrm{h}] & \text { yield [\%] } & \text { ee [\%] } \\ 1 & \text { 20a }(\mathrm{Ph}) & 24 & \mathrm{nr} & \\ 2 & \mathbf{2 0 b}(\mathrm{Ts}) & 4.5 & 99 & 4 \\ 3 & \mathbf{2 0 c}\left(\mathrm{P}(\mathrm{O}) \mathrm{Ph}_{2}\right) & 24 & 87 & 67(\mathrm{~S}) \\ 4 & \mathbf{2 0 d}\left(\mathrm{COCH}_{3}\right) & 24 & 95 & 63 \\ 5 & \mathbf{2 0 e}\left(\mathrm{CO}_{2} \mathrm{Me}\right) & 24 & 64 & 83 \\ 6 & \mathbf{2 0 f}\left(\mathrm{CO}_{2} \text { tBu }\right) & 24 & 76 & 90(R)\end{array}$

and the desired product 15G was obtained in $97 \%$ yield with $86 \%$ ee (Table 2, entry 7). ${ }^{[14]}$ Furthermore, the reaction could be applied to a wide range of substrates $16 \mathbf{A}-\mathbf{E}$ bearing various $\beta$-substituents and nucleophiles 14a-c as illustrated in Table 3. When the reaction was carried out in a $0.1 \mathrm{M}$ solution, the enantioselectivity of Michael adducts 17A-E improved up to $93 \%$ ee (entries 1-5). It is noteworthy that ees of the products $18 \mathrm{~A}-\mathbf{E}$ and $19 \mathrm{~A}-\mathbf{E}$ obtained by the reaction with methyl $\alpha$-cyanoacetate $14 \mathrm{~b}$ and nitromethane $\mathbf{1 4 c}$ remained fairly high (80-92\% ee) even at elevated temperature $\left(60-80{ }^{\circ} \mathrm{C}\right)$ (entries 6-13).

\section{Asymmetric Nucleophilic Addition to Electron-deficient $\mathbf{C}=\mathbf{N}$ and $\mathrm{N}=\mathrm{N}$ Double Bonds}

At the time that we started the studies on the asymmetric thiourea-catalyzed reactions, there had been several reports concerning enantioselective thiourea-catalyzed nucleophilic addition to imines. ${ }^{[7]}$ However, nucleophiles employed in these reactions are restricted to $\mathrm{HCN}$, dialkyl phosphites, and ketene silyl acetals. To extend the synthetic versatility of the thiourea-catalyzed reactions, we screened several active methylene compounds such as nitroalkanes, malonates, and $\beta$-keto esters for the nucleophilic reaction with aldimines and azo compounds.

\subsection{Enantioselective Aza-Henry (Nitro-Mannich) Reaction}

The aza-Henry reaction, nucleophilic addition of nitroalkanes to imines, is a useful carbon-carbon bond-forming process, because the obtained $\beta$-nitroamines can be transformed into valuable compounds such as vicinal diamines and $\alpha$-amino acids by reduction and Nef reaction of the nitro moiety. Before our report, there had been only two reports concerning the catalytic asymmetric aza-Henry reaction. ${ }^{[15]}$ However, each reaction is limited to a few substrates or moderate enantioselectivity. We envisaged that the desired nitronate anion could be produced from nitroalkane with the bifunctional thiourea via the hydrogenbonding activation by the thiourea moiety and subsequent deprotonation by the neighboring tertiary amino group $(\mathbf{C} \rightarrow . \mathbf{D}$ in Fig. 4). Therefore, the catalyst would promote the asymmetric aza-Henry reaction with a variety of imines.

We initially screened several imines 20a-f that had electron-withdrawing groups in the presence of thiourea $\mathbf{2 a}(10 \mathrm{~mol} \%)$ and nitromethane (10 equiv.) in dichloromethane at room temperature (Table 4). ${ }^{[16]}$ Among the imines examined, N-Boc imines $20 f$ gave the best result in terms of chemical yield and enantiomeric excess ((R)-21f: 76\%, 90\% ee ), while the reactions with N-phosphinoylimine 20c and N-acetylimine 20d provided the desired products with moderate enantioselectivity (entries
1-6). From the standpoint of the synthetic advantages of $\mathrm{N}$-protecting groups in the following transformation, N-Boc imines would be the best choice as a starting material. It is noteworthy that aza-Henry reaction with $\mathrm{N}$-phosphinoylimine 20c afforded the corresponding antipode adduct $(S)$-21c under the same reaction conditions as that with $20 f$.

Further experiments of the reaction revealed that the selectivity (ee) improved by simply decreasing the reaction temperature to $-20{ }^{\circ} \mathrm{C}$, giving the $\beta$-nitroamine $24 \mathrm{~A}$ in $90 \%$ yield with $94 \%$ ee (Scheme 4 ). Under the optimal reaction conditions, a wide range of $\mathrm{N}$-Boc imines 22B-F could be applied to this reaction, giving the corresponding adducts $\mathbf{2 4 B}-\mathbf{F}$ with high enantioselectivity irrespective of substituents on the phenyl group and aromatic rings of the aldimines. To investigate whether the reaction proceeded in a diastereo- and enantioselective manner, a series of nitroalkanes 23 was reacted with $\mathrm{N}-\mathrm{Boc}$ imine 22A. As shown in Scheme 4, the corresponding syn$\beta$-nitroamines 24 were always obtained as major products with good diastereo- and enantioselectivity (89-99\% ee), irrespective of alkyl chain length and functional group of nitroalkanes. Since other N-Boc imines 22B-F could be used as a reacting partner, the scope of the reaction is quite broad with respect to the nitroalkanes and $\mathrm{N}$-Boc imines. To demonstrate the utility of the obtained aza-Henry adducts, we have 


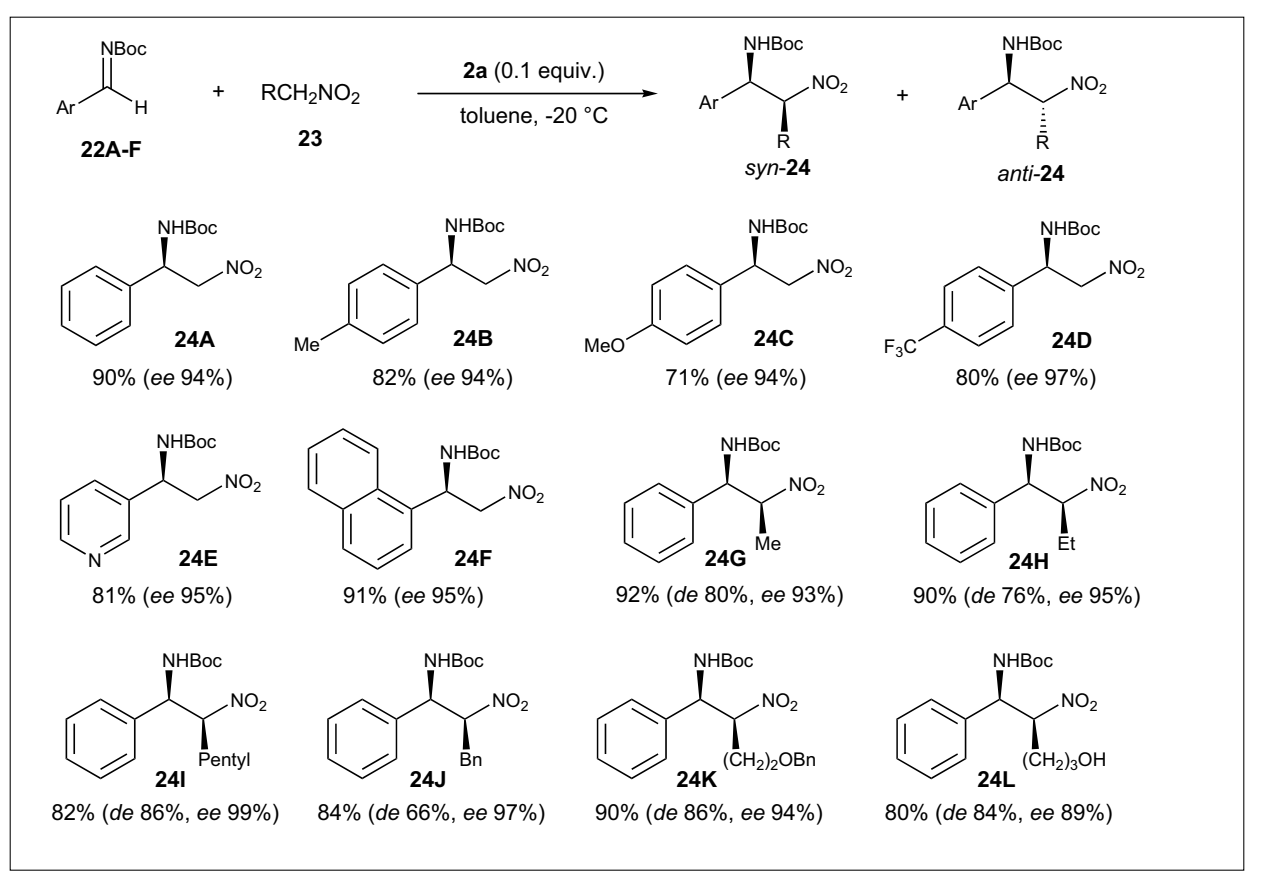

Scheme 4. Diastereo- and enantioselective aza-Henry reaction of N-Boc imines 22 and nitroalkanes 23

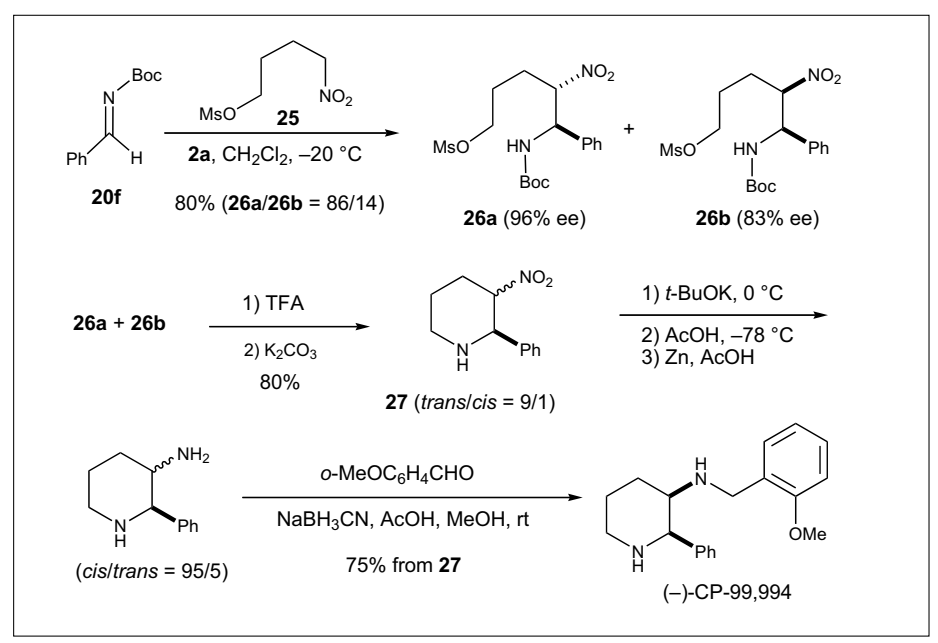

Scheme 5. Asymmetric synthesis of (-)-CP-99,994

Table 5. Reaction of $\beta$-ketoester 28A with N-Boc imine 20 catalyzed by $2 \mathbf{a}$

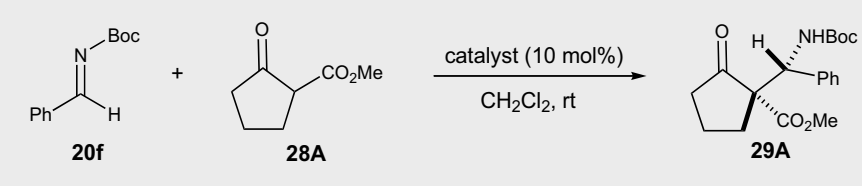

$\begin{array}{cccccc}\text { entry } & \text { catalyst } & \text { time }[\mathrm{h}] & \text { yield [\%] } & d r & \text { ee [\%] } \\ 1 & \text { none } & 48 & 67 & 68: 32 & \\ 2 & \mathrm{Et}_{3} \mathrm{~N} & 8 & 93 & 60: 40 & \\ 3 & { }^{i} \mathrm{Pr}_{2} \mathrm{NEt} & 8 & 87 & 60: 40 & \\ 4 & \mathrm{DBU} & 8 & 86 & 66: 34 & \\ 5 & \mathbf{2 a} & 9 & 98 & 91: 9 & 82^{\mathrm{b}} \\ 6^{\mathrm{a}} & \mathbf{2 a} & 72 & 89 & 92: 8 & 88^{\mathrm{b}} \\ { }^{\mathrm{a}} \text { The reaction was carried at }-20{ }^{\circ} \mathrm{C} \text {. }^{\mathrm{b}} \text { ee is for major isomer. } & & \end{array}$

achieved a six-step synthesis of chiral (-)CP-99,994 from N-Boc imine 20f and nitroalkane 25 in $48 \%$ yield (Scheme 5). ${ }^{[16 b]}$

\subsection{Enantioselective Mannich Reaction of 1,3-Dicarbonyl Compounds.}

In recent years, the enantioselective direct Mannich reaction has attracted much attention in approaches toward chiral $\beta$ amino acid derivatives. ${ }^{[17]}$ The asymmetric Mannich reaction with a symmetric C-nucleophile such as a dialkyl malonate has been widely investigated. In contrast, the reaction with an unsymmetrical nucleophile allows the generation of two stereogenic centers in a single carbon-carbon bond-forming process; thus, the control of both enantio- and diastereoselectivities is a challenging task. Cinchona alkaloids bearing the thiourea moiety were recently shown to be effective catalysts for the direct Mannich reaction by Deng's and Dixon's groups independently. ${ }^{[18]}$ We became interested in possibility of simple thiourea $\mathbf{2 a}$ in direct Mannich reactions with unsymmetrical prochiral nucleophiles.

We first tried the Mannich reaction of N-Boc-imine 20f with cyclic 1,3-dicarbonyl compound 28A in the presence of several catalysts (Table 5). Although the reaction proceeded slowly even in the absence of catalyst, addition of organic bases such as $\mathrm{Et}_{3} \mathrm{~N}$, $(i \text {-Pr })_{2} \mathrm{NEt}$ and DBU $(10 \mathrm{~mol} \%)$ promoted the reaction, giving the desired products in good yield, but with moderate diastereoselectivities (entries 1-4). In contrast, thiourea 2a worked well as an effective catalyst for the control of both enantio- and diastereoselectivities (entry 5). The stereoselective construction of quaternary carbon center was achieved with $10 \mathrm{~mol} \%$ of thiourea $2 \mathbf{a}$ at $-20{ }^{\circ} \mathrm{C}$, furnishing a $92: 8$ diastereomeric mixture of the desired adducts $29 \mathrm{~A}$ in $89 \%$ yield with $88 \% e e$ (entry 6).

The scope of enantio- and diastereoselective reaction catalyzed by thiourea $\mathbf{2 a}$ a was next investigated under the optimized conditions (Scheme 6). As expected, the reactions of several N-Boc imines with diethyl malonate took place with high enantioselectivity to give the corresponding products $\mathbf{2 9}$ with no other adducts. On the other hand, only a modest enantioselectivity of 29B was observed in the reaction with prochiral six-membered $\beta$ ketoester 28B, although diastereoselectivity still remained high. The seven-membered ketoester 28C also produced adduct 29C with an excellent enantioselectivity. The diastereoselectivity was shown to be dependent on the structure of nucleophiles. The use of five-membered 1,3-diketone $28 \mathrm{E}$ bearing a 1-oxoethyl group led to decreased diastereoselectivity, but high degree of enantiocontrol was maintained. ${ }^{[19]}$ 


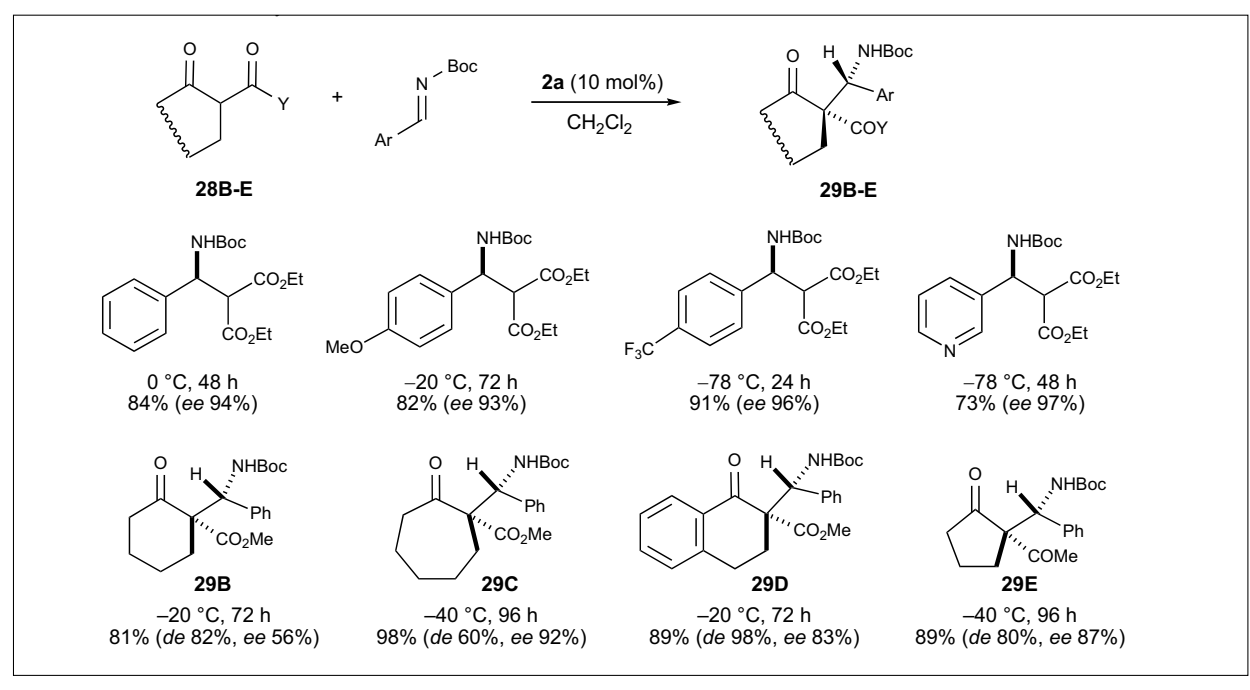

Scheme 6. Thiourea-catalyzed Mannich reaction with N-Boc imines

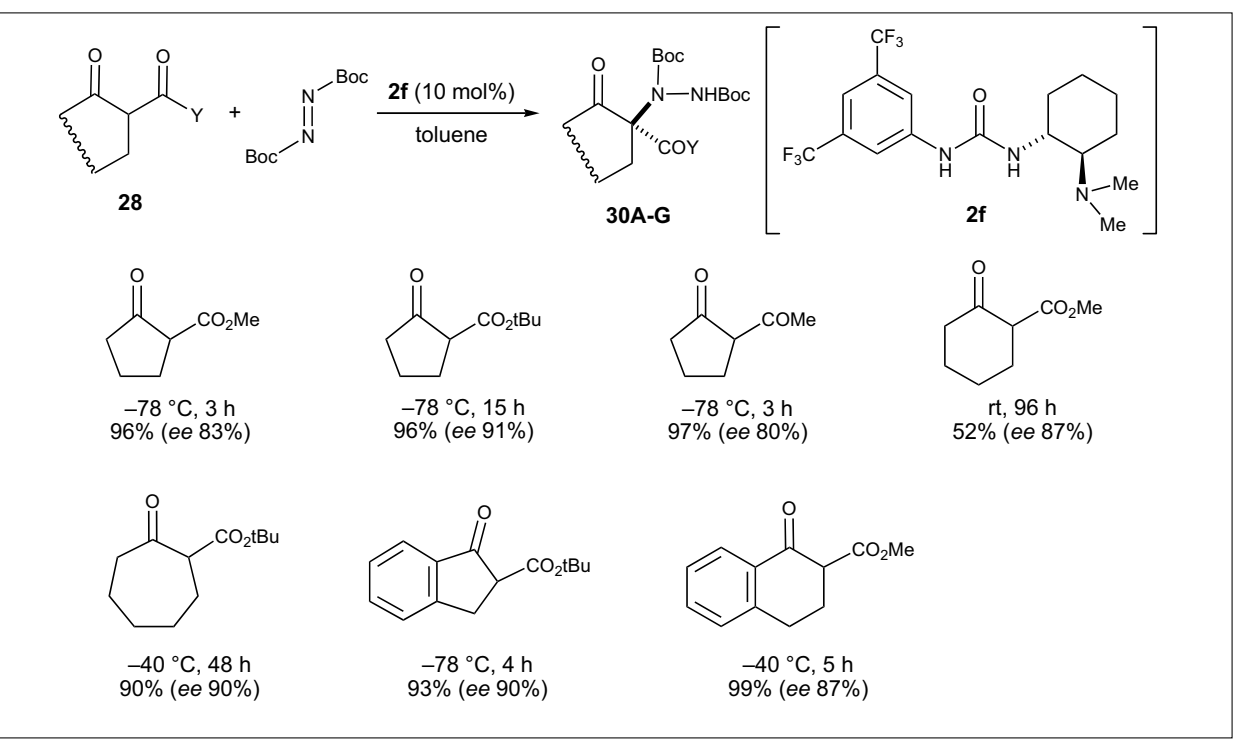

Scheme 7. Urea-catalyzed hydrazination of 1,3-dicarbonyl compounds

\subsection{Enantioselective Hydrazination of $\beta$-Ketoesters}

From the viewpoint of development of neuroactive glutamate analogues, cyclic $\alpha$-quaternary $\alpha$-amino acids have attracted great attention. The highly enantioselective synthesis of the $\alpha, \alpha$-disubstituted $\alpha$-amino acids involves chiral Lewis acid-catalyzed amination of $\beta$-ketoesters and organocatalytic amination of $\alpha$-cyanoesters as reported by the groups of Jørgensen and Deng. ${ }^{[20]}$ In these reactions, high enantioselectivity was observed, but only acyclic substrates were examined. In contrast, to the best of our knowledge, the use of cyclic $\beta$-ketoesters has met with limited success in organocatalytic $\alpha$-hydrazination. ${ }^{[21]}$

We applied the bifunctional thiourea $\mathbf{2 a}$ for the $\alpha$-amination of cyclic $\beta$-ketoesters with azodicarboxylate, based on Pihko and Pohjakallio's finding ${ }^{[21 a]}$ that the reaction proceeded without catalysts in protic solvents such as EtOH as well as the structural structure-activity relationship of these catalysts revealed that thiourea $\mathbf{2 a}$ was the best catalyst for 1,4- and 1,2-additions of various nucleophiles such as malonates, $\beta$-ketoesters, 1,3-diketones, nitroalkanes, malononitrile, and $\alpha$-cyanoacetate into nitroolefins, N-Boc aldimines, $\alpha, \beta$-unsaturated imides, and azodicarboxylate. In these reactions, the double hydrogenbonding activation of electrophiles bearing nitro, imide, and carbamate groups by the thiourea moiety and simultaneous deprotonation of the nucleophiles by the dimethylamino group of bifunctional thiourea 2a were proved to play a crucial role for enhancing both reaction rate and enantioselectivity.

From the standpoint of sustainable chemistry, these organocatalyst-mediated reactions would be desirable tools for preparing organic compounds and, therefore, more sophisticated multi-functional organocatalysts should be created for the development of new methodologies for multicomponent and tandem reactions.

Received: March 22, 2007

[1] a) T. R. Kelly, M. K. Kim, J. Am. Chem. Soc. 1994, 116, 7072; b) F. P. Schmidtchen, M. Berger, Chem. Rev. 1997, 97, 1609; c) B. R. Linton, M. S. Goodman, A. D. Hamilton, Chem. Eur. J. 2000, 6, 2449; d) L. J. Prins, D. N. Reinhoudt, P. Timmerman, Angew. Chem., Int. Ed. 2001, 40, 2382.

[2] a) T. R. Kelly, P. Meghani, V. S. Ekkundi, Tetrahedron Lett. 1990, 31, 3381; b) M. C. Etter, Acc. Chem. Res. 1990, 23, 120; c) M. C. Etter, Z. Urbañczyk-Lipkowska, M. Zia-Ebrahimi, T. W. Panunto, J. Am. Chem. Soc. 1990, 112, 8415.

[3] For reviews on urea and thiourea catalysis, see; a) P. R. Schreiner, Chem. Soc. Rev. 2003, 32, 289; b) P. M. Pihko, Angew. Chem., Int. Ed. 2004, 43, 2062; c) Y. Takemoto, Org. Biomol. Chem. 2005, 3, 4299; d) M. S. Taylor, E. N. Jacobsen, Angew. Chem., Int. Ed. 2006, 45, 1520; e) S. J. Connon, Chem. Eur. J. 2006, 12, 5418; f) T. Akiyama, J. Itoh, K. Fuchibe, $A d v$. Synth. Catal. 2006, 348, 999.

[4] a) D. P. Curran, L. H. Kuo, J. Org. Chem. 1994, 59, 3259; b) D. P. Curran, L. H. Kuo, Tetrahedron Lett. 1995, 36, 6647; c) C. S. Wilcox, E. Kim, D. Romano, L. H. Kuo, A. L. Burt, D. P. Curran, Tetrahedron 1995, 51, 621.

[5] a) P. R. Schreiner, A. Wittkopp, Org. Lett. 2002, 4, 217; b) A. Wittkopp, P. R. Schreiner, Chem. Eur. J. 2003, 9, 407; c) C. M. Kleiner, P. R. Schreiner, Chem. Commun. 2006, 4315.

[6] a) T. Okino, Y. Hoashi, Y. Takemoto, Tetrahedron Lett. 2003, 44, 2817; b) D. Menche, J. Hassfeld, J. Li, G. Menche, A. Ritter, S. Rudolph, Org. Lett. 2006, 8, 741; c) A. E. Mattson, A. M. Zuhl, T. E. Reynolds, K. A. Scheidt, J. Am. Chem. Soc. 
2006, 128, 4932; d) S. C. Pan, J. Zhou, B. List, Synlett 2006, 3275.

[7] a) M. S. Sigman, E. N. Jacobsen, J. Am. Chem. Soc. 1998, 120, 4901; b) M. S. Sigman, P. Vachal, E. N. Jacobsen, Angew. Chem., Int. Ed. 2000, 39, 1279; c) P.; Vachal, E. N. Jacobsen, J. Am. Chem. Soc. 2002, 124, 10012; d) A. G. Wenzel, E. N. Jacobsen, J. Am. Chem. Soc. 2002 , 124, 12964; e) G. D. Joly, E. N. Jacobsen, J. Am. Chem. Soc. 2004, 126, 4102; f) M. S. Taylor, E. N. Jacobsen, J. Am. Chem. Soc. 2004, 126, 10558; g) T. P. Yoon, E. N. Jacobsen, Angew. Chem., Int. Ed. 2005 , 44, 466; h) M. S. Taylor, N. Tokunaga, E. N. Jacobsen, Angew. Chem., Int. Ed. 2005 , 44, 6700; i) D. E. Fuerst, E. N. Jacobsen, J. Am. Chem. Soc. 2005, 127, 8964; j) I. T. Raheem, E. N. Jacobsen, Adv. Synth. Catal. 2005, 347, 1701; k) H. Huang, E. N. Jacobsen, J. Am. Chem. Soc. 2006, 128, 7170.

[8] a) D. J. Maher, S. J. Connon, Tetrahedron Lett. 2004, 45, 1301; b) Y. Sohtome, A. Tanatani, Y, Hashimoto, K. Nagasawa, Tetrahedron Lett. 2004, 45, 5589; c) B.-J. Li, L. Jiang, M. Liu, Y.-C. Chen, L.-S. Ding, Y. Wu, Synlett 2005, 603; d) A. Berkessel, F. Cleemann, S. Mukherjee, T. N. Müller, J. Lex, Angew. Chem., Int. Ed. 2005, 44, 807; e) B. Vakulya, S. Varga, A. Csámpai, T. Soós, Org. Lett. 2005, 7, 1967; f) S. H. McCooey, S. J. Connon, Angew. Chem., Int. Ed. 2005, 44, 6367; g) R. P. Herrera, V. Sgarzani, L. Bernardi, A. Ricci, Angew. Chem., Int. Ed. 2005, 44, 6576; h) J. Wang, H. Li, X. Yu, L. Zu, W. Wang, Org. Lett. 2005, 7, 4293; i) J. Wang, H. Li, W. Duan, L. Zu, W. Wang, Org. Lett. 2005, 7, 4713; j) A. Berkessel, F. Cleemann, S. Mukherjee, Angew. Chem., Int. Ed. 2005, 44, 7466; k) J. Ye, D. J. Dixon, P. S. Hynes, Chem. Commun. 2005, 4481; 1) S. B. Tsogoeva, D. A. Yalalov, M. J. Hateley, C. Weckbecker, K. Huthmacher, Eur. J. Org. Chem. 2005, 4995; m) Y. Sohtome, Y. Hashimoto, K. Nagasawa, Adv. Synth. Catal. 2005, 347, 1643; n) T. Marcelli, R. N. S. van der Haas, J. H. van Maarseveen, H. Hiemstra, Angew. Chem., Int. Ed. 2006 , 45, 929; o) D. J. Dixon, R. D. Richardson, Synlett 2006, 81; p) A. Berkessel, K. Roland, J. M. Neudörfl, Org. Lett. 2006, 8, 4195; q) J. Wang, H. Li, L. Zu, W. Jiang, H. Xie, W. Duan, W. Wang, J. Am. Chem. Soc. 2006, 128, 12652.

[9] a) M. Kitamura, S. Suga, K. Kawai, R. Noyori, J. Am. Chem. Soc. 1986, 108, 6071; b) E. J. Corey, R. K. Bakshi, S. Shibata, J. Am. Chem. Soc. 1987, 109, 5551; c) M. Shibasaki, H. Sasai, T. Arai, Angew. Chem., Int. Ed. 1997, 36, 1236; d) H. Gröger, Chem. Eur. J. 2001, 7, 5246; e) J. Ma, D. Cahard, Angew. Chem., Int. Ed. 2004, 43,4566 .

[10] a) T. Okino, Y. Hoashi, Y. Takemoto, $J$. Am. Chem. Soc. 2003, 125, 12672; b) T. Okino, Y. Hoashi, T. Furukawa, X. Xu, Y.
Takemoto, J. Am. Chem. Soc. 2005, 127, 119; c) H. Miyabe, S. Tuchida, M. Yamauchi, Y. Takemoto, Synthesis 2006, 3295.

[11] a) J. Ji, D. M. Barnes, J. Zhang, S. A. King, S. J. Wittenberger, H. E. Morton, J. Am. Chem. Soc. 1999, 121, 10215; b) H. Li, Y. Wang, L. Tang, L. Deng, J. Am. Chem. Soc. 2004, 126, 9906; c) M. Watanabe, A. Ikagawa, H. Wang, K. Murata, T. Ikariya, J. Am. Chem. Soc. 2004, 126, 11148; d) D. A. Evans, D. Seidel, J. Am. Chem. Soc. 2005, 127, 9958; e) M. Terada, H. Ube, Y. Yaguchi, J. Am. Chem. Soc. 2006, 128, 1454.

[12] a) Y. Hoashi, T. Yabuta, Y. Takemoto, Tetrahedron Lett. 2004, 45, 9185; b) Y. Hoashi, T. Yabuta, P. Yuan, H. Miyabe, Y. Takemoto, Tetrahedron 2006, 62, 365.

[13] a) K. Itoh, S. Kanemasa, J. Am. Chem. Soc. 2002, 124, 13394; b) M. S. Taylor, E. N. Jacobsen, J. Am. Chem. Soc. 2003, 125,11204 ; c) D. A. Evans, R. J. Thomson, F. Franco, J. Am. Chem. Soc. 2005, 127,10816

[14] a) Y. Hoashi, T. Okino, Y. Takemoto, Angew. Chem., Int. Ed. 2005, 44, 4032; b) T. Inokuma, Y. Hoashi, Y. Takemoto, J. Am. Chem. Soc. 2006, 128, 9413.

[15] a) K. Yamada, S. J. Harwood, H. Gröger, M. Shibasaki, Angew. Chem., Int. Ed. 1999, 38, 3504; b) K. R. Knudsen, T. Risgaard, N. Nishiwaki, K. V. Gothelf, K. A. Jørgensen, J. Am. Chem. Soc. 2001, 123, 5843; c) F. Fini, V. Sgarzani, D. Pettersen, R. P. Herrera, L. Bernardi, A. Ricci, Angew. Chem., Int. Ed. 2005, 44, 7975.

[16] a) T. Okino, S. Nakamura, T. Furukawa, Y. Takemoto, Org. Lett. 2004, 6, 625; b) X. $\mathrm{Xu}, \mathrm{T}$. Furukawa, T. Okino, H. Miyabe, Y. Takemoto, Chem. Eur. J. 2006, 12, 466.

[17] For a review of catalytic asymmetric direct Mannich reactions, See: A. Córdova, Acc. Chem. Res. 2004, 37, 102. Some recent examples of direct asymmetric Mannich reactions, see: a) A. Ting, S. Lou, S. E. Schaus, Org. Lett. 2006, 8, 2003; b) S. Lou, B. M. Taoka, A. Ting, S. E. Schaus, J. Am. Chem. Soc. 2005, 127, 11256; c) Y. Hamashima, N. Sasamoto, D. Hotta, H. Somei, N. Umebayashi, M. Sodeoka, Angew. Chem., Int. Ed. 2005, 44, 1525; d) D. Uraguchi, M. Terada, J. Am. Chem. Soc. 2004, 126, 5356; e) S. Matsunaga, T. Yoshida, H. Morimoto, N. Kumagai, M. Shibasaki, J. Am. Chem. Soc. 2004, 126, 8777; f) W. Zhuang, S. Saaby, K. A. Jørgensen, Angew. Chem., Int. Ed. 2004, 43, 4476; g) A. J. A. Cobb, D. M. Shaw, S. V. Ley, Synlett 2004, 558; h) A. Córdova, Chem. Eur. J. 2004, 10, 1987.

[18] a) J. Song, Y. Wang, L. Deng, J. Am. Chem. Soc. 2006, 128, 6048; b) A. L. Tillman, J. Ye, D. J. Dixon, Chem. Commun. 2006, 1191.

[19] The manuscript is submitted.

[20] a) M. Marigo, K. Juhl, K. A. Jørgensen, Angew. Chem., Int. Ed. 2003, 42, 1367; b) S. Saaby, M. Bella, K. A. Jørgensen, J. Am.
Chem. Soc. 2004, 126, 8120; c) X. Liu, H. Li, L. Deng, Org. Lett. 2005, 7, 167.

[21] a) P. M. Pihko, A. Pohjakallio, Synlett 2004, 2115; b) J. T. Suri, D. D. Steiner, C. F. Barbas, III, Org. Lett. 2005, 7, 3885.

[22] X. Xu, T. Yabuta, P. Yuan, Y. Takemoto, Synlett 2006, 137. 